\title{
IDEÁRIO REPUBLICANO NOS CAMPOS GERAIS: A CRIAÇÃO DO GRUPO ESCOLAR CONSELHEIRO JESUÍNO MARCONDES (1907)
}

\author{
Lucia Mara de Lima Padilha \\ Universidade Estadual de Ponta Grossa - UEPG/HISTEDBR
}

\begin{abstract}
RESUMO
O presente trabalho refere-se à pesquisa de mestrado, do programa de Pós-Graduação em Educação da Universidade Estadual de Ponta Grossa - PR, sobre o grupo escolar "Conselheiro Jesuíno Marcondes", na cidade de Palmeira nos Campos Gerais - Paraná. Trata-se de uma instituição regional de ensino a partir da qual se procurou estabelecer relações entre o contexto nacional e o local, uma vez que está dentro do projeto republicano de instauração de Grupos Escolares no país, cujo objetivo era a expansão da escolarização visando reduzir o alto índice de analfabetismo e de forma ideológica, doutrinar e "civilizar" a sociedade. Por ser uma instituição criada numa região com várias colônias de imigrantes, procurou-se também verificar as questões mais gerais no contexto da sociedade, do Estado, da organização das classes e grupos sociais dominantes que influenciaram nas relações de adaptação desses imigrantes no país.
\end{abstract}

Palavras-chave: Escola Pública. Palmeira. Paraná.

\section{REPUBLICAN IDEALS IN CAMPOS GERAIS: THE CREATION OF JESUÍNO MARCONDES SCHOOL GROUP (1907)}

\begin{abstract}
The present work refers to the master thesis, from the graduate program of the State University of Ponta Grossa - PR, about the school "Conselheiro Jesuíno Marcondes", in the city of Palmeira in Campos Gerais - Parana. It is about a regional teaching institution from which the relation between the national context and the local one was sought to be established, once that it was in the republican project of introduction of School Groups in the country, whose objective was the expansion of schooling, aiming at reducing the high level of illiteracy, and in an ideological manner, doctrine and "civilize" the society. Because it is an institution created in a region with various immigrant colonies, it was also sought to verify the most general questions in the society's context, the State's, the classes organization and dominant social groups that influenced in the ratio adjustment of these immigrants in the country.
\end{abstract}

Keywords: Public School. Palmeira. Paraná.

\section{INTRODUÇÃO}

A delimitação empreendida nessa pesquisa ficou circunscrita no período histórico entre os anos de 1889 a 1907 e engloba a fase inicial do Regime Republicano no Brasil. Teve como finalidade realizar a reconstrução histórica de uma instituição escolar pública na região dos Campos Gerais - PR, criada no início do século XX dentro do ideário republicano, o "Grupo Escolar Conselheiro Jesuíno Marcondes". Entretanto, na realização do estudo, foram também sendo explicitados alguns elementos importantes, como por 
exemplo, a origem da divisão da sociedade de classes e a criação da escola pública para todos como estratégia da ordem capitalista.

Essa pesquisa faz parte do projeto ${ }^{i}$ de "Reconstrução histórica das instituições escolares nos Campos Gerais na primeira metade do século XX", que teve como objetivo o resgate de fontes primárias das Instituições Escolares Públicas, nos Campos Gerais ${ }^{\mathrm{ii}}$ - PR.

O primeiro momento desse estudo foi caracterizado pelo levantamento e pela catalogação das fontes primárias e secundárias relacionadas ao grupo escolar Conselheiro Jesuíno Marcondes e à formação da sociedade de Palmeira, pois para a realização da análise do referido objeto de pesquisa foi necessário compreender as relações econômicas, políticas e sociais do contexto no qual o mesmo estava inserido. Entretanto é preciso afirmar que, mesmo se tratando de uma pesquisa que se propôs a resgatar as fontes históricas de uma determinada região, a mesma não se desenvolveu desvinculada da totalidade das relações do contexto nacional, visto que o particular não dá conta do todo.

Em uma sociedade dividida em classes antagônicas (burguesia e o proletariado) estudar a primeira Instituição escolar em Palmeira é pensar em uma educação de classes. Como são as idéias dominantes de uma época que dominam a sociedade, na sociedade brasileira são as idéias burguesas que predominam.

A instituição escolar é criada então para corresponder a determinados interesses desta classe dominante e ela, a Escola, será um dos instrumentos na sociedade capitalista, para reprodução desta classe. E por se tratar de uma escola criada no período republicano, como já citado, onde o sistema de ensino inicia sua organização nas quatro primeiras séries de escolarização no país, ela "[...] cumpria funções sociais determinadas, sem deixar aparentes as desigualdades que se solidificaram durante a República com sua legitimação e sua manutenção pelo Estado" (NASCIMENTO, apud, VIDAL, 2006, p.325).

Essa pesquisa teve por objetivo realizar a reconstrução histórica do "Grupo Escolar Conselheiro Jesuíno Marcondes", uma instituição pública da região dos Campos Gerais PR, criada no início do século XX dentro do ideário republicano. Para dar conta dessa problemática e compreendê-la foram elencadas as seguintes categorias de análise (Estado, Trabalho, Educação), com as quais nos aproximamos do objeto em estudo.

O estudo foi estruturado e organizado a partir dos pressupostos teóricometodológicos do materialismo histórico e dialético, que propõe para a investigação de determinado objeto que se parta das condições concretas de existência, superando as concepções idealistas e metafísicas da história, pois a dialética encara as coisas

[...] em suas conexões, em sua dinâmica, em seu processo de gênese e caducidade. A partir dela pode-se afirmar que todo ser é, no mesmo momento, ele mesmo e um outro. [...] Da forma como foi posta a questão em A Ideologia Alemã, fica claramente demarcado que o postulado materialista era considerado básico tanto do ponto de vista ontológico quanto do epistemológico, isto é, a matéria é básica tanto como princípio explicativo do mundo, quanto como ponto de partida para o conhecimento que se constrói sobre ele (LOMBARDI, 1993, p. 396-397).

Desta forma considera-se fundamental estudar o processo de constituição do grupo escolar "Conselheiro Jesuíno Marcondes", utilizando o método dialético, pois o mesmo possibilitará estabelecer relações entre os fatores sócio-políticos e econômicos do país por meio de uma análise dinâmica e totalizante da realidade, não considerando os fatos isolados, porém influenciados pela totalidade.

O procedimento metodológico adotado para o desenvolvimento da pesquisa foi, inicialmente a realização do levantamento das fontes documentais e iconográficas, como: 
Leis, Decretos, Regulamentos, Portarias, Atas de reuniões, fotografias, mapas, desenhos e Jornais da época, encontrados no Grupo Escolar em estudo, no Museu da cidade de Palmeira, na Casa da Memória de Ponta Grossa, no Arquivo Público do Paraná - PR e no Museu Campos Gerais - PR, e posteriormente, de pose desse material devidamente copiado e digitalizado, organizou-se um banco de dados específico que foi armazenado em um CDROM.

\section{O ideário republicano brasileiro e a educação}

Inicialmente, para a compreensão da estrutura econômica, política e social, presente no período republicano brasileiro no final do século XIX e início do século XX, período transitório entre a abolição do trabalho escravo e inserção do trabalho livre e assalariado no país, fez-se necessário tomar como fio condutor a divisão da sociedade em classes distintas e a divisão social do trabalho, fatores esses que influenciaram diretamente na criação de uma educação formalizada e na criação da escola como instituição, para posteriormente adentrar no período histórico delimitado da pesquisa e analisar a criação da escola pública, gratuita e estatal no Brasil.

Nas sociedades primitivas, denominadas tribais, o homem vivia em comunidade, assentada sobre a propriedade comum da terra e unida por "[...] laços de sangue, os seus membros eram indivíduos livres, com direitos iguais. O que era produzido em comum era repartido com todos, e imediatamente consumido" (PONCE, 1963, p.15). A educação acontecia naturalmente, as crianças imitavam e reproduziam os atos realizados pelos adultos em suas atividades rotineiras como a pesca e a caça.

O período primitivo é marcado por lentas e diferenciadas transformações nas formas de trabalho e no emprego da terra para a agricultura, utilizada para o plantio e também para o pastoreio, esse desenvolvimento, acrescido da utilização do trabalho animal, da criação da roda e do transporte marítimo, trouxe consigo a produção excedente dos bens materiais, e "[...] tão cedo o bem-estar da tribo aumentou, por causa das novas técnicas de produção, os prisioneiros de guerra passaram a ser desejadosiii , e o inimigo vencido passou a ter sua vida garantida com a condição de transformar-se em escravo" (PONCE, 1963, p. 23, grifos do autor).

A sociedade, até então homogênea, passa a dividir-se em classes antagônicas, a propriedade, bem comum de todos os membros da tribo, passa a ser privada propiciando assim a divisão da humanidade. A religião, a educação e a separação entre os trabalhadores braçais e os "intelectuais" iv , até então inexistentes, se afirmam nesse contexto. O anseio da classe dominante pela conquista de riquezas e poder, carece de uma instituição que a defenda e legitime seus direitos de exploração, surge aí o representante dessa classe, o Estadov, que "[...] situado aparentemente por cima das classes em luta, suprimisse os conflitos abertos destas e só permitisse a luta de classes no campo econômico, numa forma dita legal" (ENGELS, 1991, p.190).

Consequentemente à divisão do trabalho, a educação que até então acontecia de forma espontânea passa a ter objetivos definidos, sendo destinada apenas para a classe dominante, pois a mesma não tendo responsabilidades com o trabalho braçal dispunha de tempo livre para realizar atividades de lazer. "E é aí que se localiza a origem da escola. [...] como se sabe, deriva do grego e significa, etimologicamente, o lugar do ócio" (SAVIANI, 2007, p.9).

As relações econômicas, políticas e sociais que propiciaram a criação dos grupos escolares no Brasil, no final do século XIX e início do século XX, compreendem um longo processo da sociedade desde a modernidade, quando pela primeira vez com Lutero, se 
coloca a necessidade da instituição de uma escola pública, até que fossem concretizados os ideais educacionais que idealizaram a criação e institucionalização da escola pública e gratuita, com as revoluções da América e da França, que exigia “[...] uma instrução universal e de uma reorganização do saber, que acompanhará o surgimento da ciência e da indústria moderna" (MANACORDA, 1996, p.249).

No final do século XIX ocorreu um avanço econômico nas exportações de café tornando o Brasil um dos maiores exportadores do gênero. Com a abolição da escravidão ocorre a falta de braços para os trabalhos nas lavouras, de modo que, surge a necessidade de se capacitar os ex-escravos para exercerem o trabalho livre.

Percebe-se que para os negros e para os pobres teria que ser implantada uma escola diferenciada, que atendesse as necessidades básicas do capitalismo, ou seja, preparar para o trabalho. Entretanto após a abolição efetiva, em 1888, a

[...] crença de que a liberdade gradativa dos escravos deveria ser acompanhada da presença da escola para transformar "os ingênuos e os homens livres, parasitas da grande propriedade e da natureza pródiga, em trabalhadores submetidos às regras do capital [...] não se efetivou e, surpreendentemente, essas discussões desapareceram (SCHELBAUER, 1998, p. 52).

A educação voltada para a formação dos ex-escravos deixa de ser colocada como necessária quando ocorre a substituição do trabalho escravo pelo trabalhador livre, e à medida "[...] que os imigrantes se integravam às fazendas de café garantindo a continuidade da produção, os apelos à criação de colônias agrícolas, fazendas-escolas e colônias orfanológicas deixaram de ecoar" (SAVIANI, 2008, p. 164). Com a república a educação volta-se então para a formação dos ideais nacionais, incorporando a grande massa de imigrantes que traziam consigo as tradições de sua terra natal. Inserir o novo trabalhador no contexto nacional torna-se o objetivo central da proposta educativa republicana.

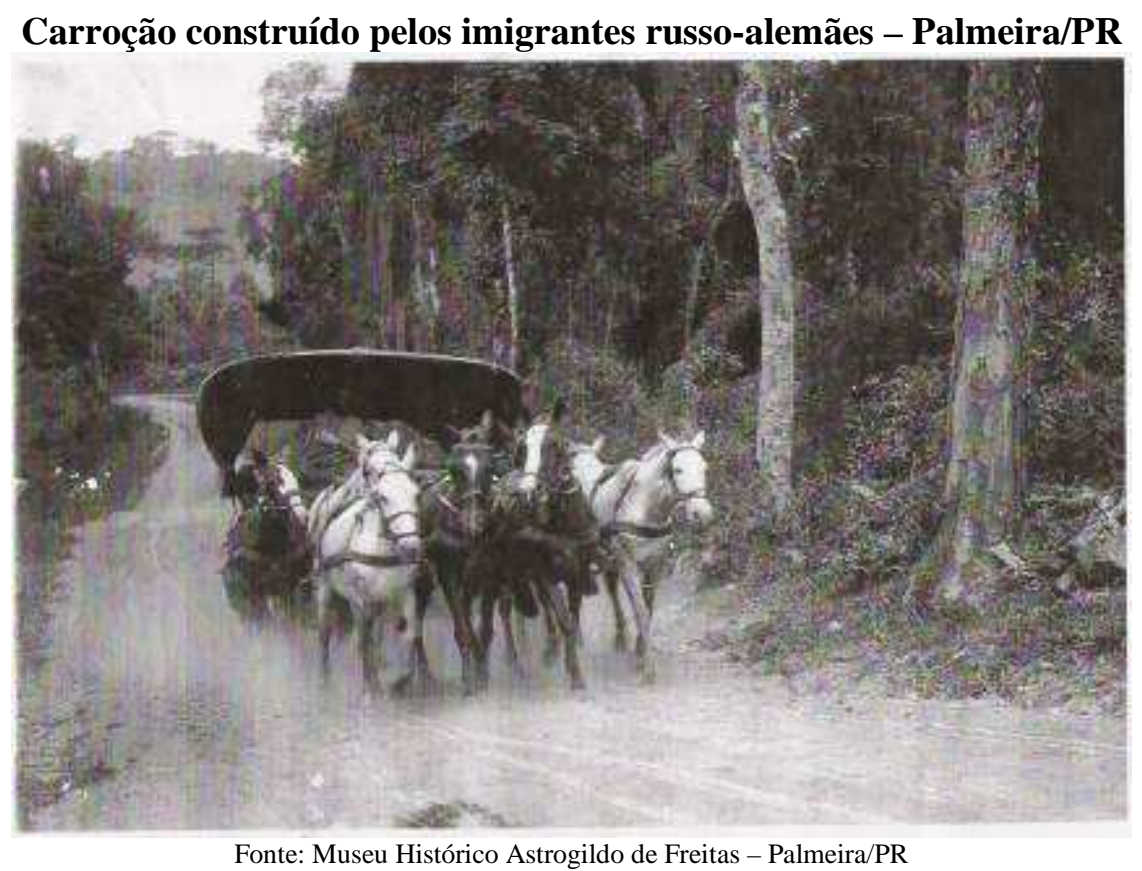


Os republicanos utilizaram-se da educação como um de seus aparatos para a divulgação de seus ideais, enfatizando a necessidade de se alfabetizar "toda" a população do país. Os discursos a favor da modernização e progresso do Brasil ressaltavam a criação de novos e modernos prédios que viessem a agrupar as escolas públicas Isoladas, formando assim os grupos escolares republicanos.

Escolas públicas, gratuitas e estatais são criadas nesse contexto, sendo a educação, colocada pelos republicanos, como a salvação do país. Nessa nova lógica de "progresso", baseado na divisão social do trabalho, o analfabetismo é visto como uma praga a ser "erradicada" do país, visto que a prioridade era a urgência em elaborarem-se possíveis reformas educacionais.

No entanto, percebeu-se que apesar de os discursos republicanos enfatizarem uma educação pública para "todos", o ensino foi elaborado e ministrado conforme o "[...] interesse de classe, e da classe burguesa que, contudo, busca se impor apresentando seus interesses como sendo de caráter universal" (SANTANA, 1996, p. 22), visto que essa educação se deu de forma diferenciada, pois deveria atender os indivíduos da sociedade de acordo com as circunstâncias e o destino de cada um.

As mudanças ocorridas no Brasil, no final do século XIX, refletiram no Paraná cuja economia, de modo geral, estava voltada para o setor de subsistência, da exploração do pinho, e da exportação da erva-mate.

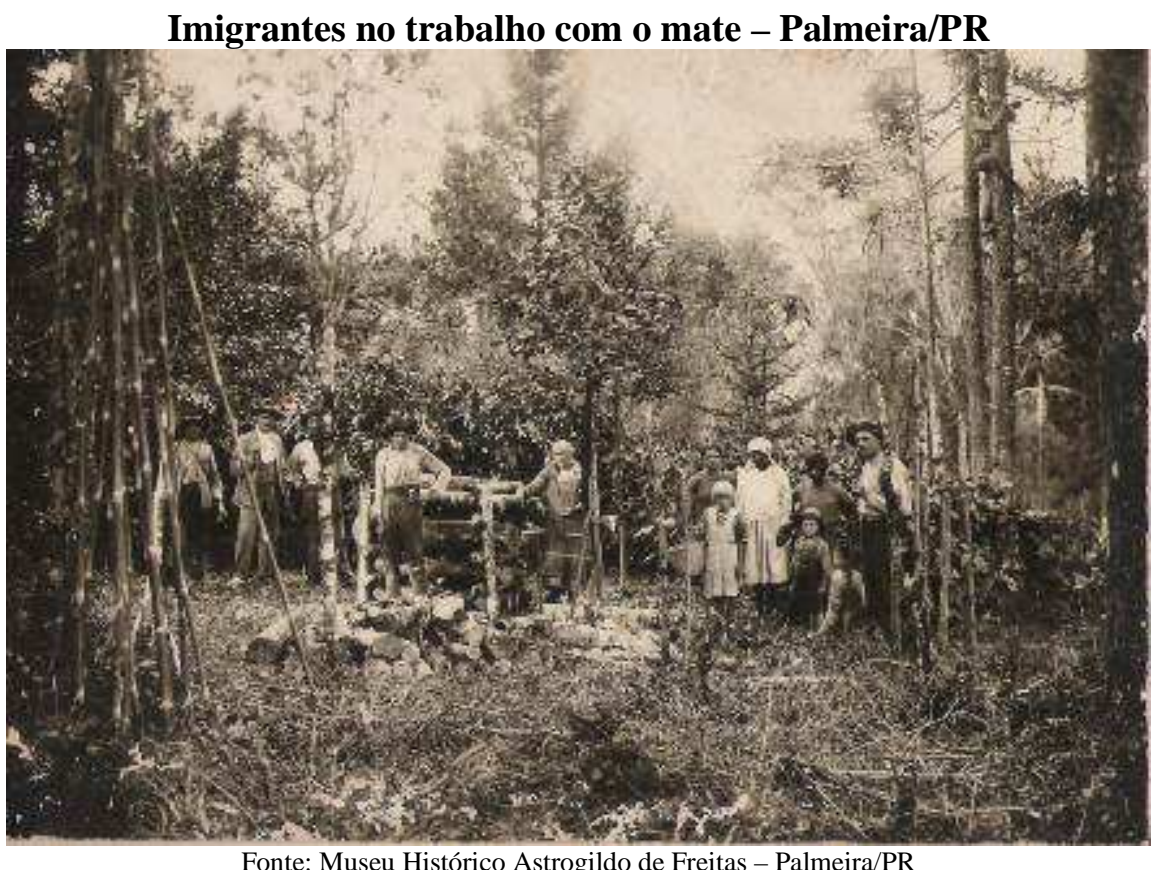

Com a vinda dos imigrantes europeus, destinados o sul do Brasil com o intuito de povoar as terras nas áreas rurais, formaram-se os diversos núcleos coloniais. Utilizando carroças e carroções os colonos transportavam a erva-mate do interior para os moinhos de beneficiamento de Curitiba, além de desenvolverem a produção agrícola nas colônias, desenvolveram também o comércio e o artesanato.

Não se pode deixar de evidenciar que ao substituir o trabalho escravo pelo trabalhado livre e assalariado, a sociedade brasileira não aboliu os antagonismos de classes. "[...] Não se fez senão substituir novas classes, novas condições de opressão, novas formas de luta às que existiram no passado" (MARX e ENGELS, 1975, p.4). O escravo liberto não se transforma em cidadão, percebe-se que, 
[...] o negro cidadão é apenas o negro que não é mais juridicamente escravo. Ele foi posto na condição de trabalhador livre, mas nem é aceito plenamente do lado de outros trabalhadores livres, brancos. [...] É o escravo que ganhou a liberdade de não ter segurança; nem econômica, nem social, nem psíquica. É uma pessoa cujo estado alienado vai manifestar-se agora plenamente, pois é na liberdade que ele compreenderá que foi e é espoliado. Ele se tornou o cidadão que deverá compreender que já não estará mais integrado, ainda que hierarquicamente na posição mais inferior, mas integrado. Livre, ele estará só escoteiro dos meios de subsistência, dos instrumentos de produção. E tomará consciência de que não tem meios de consegui-los, salvo pela venda da sua força de trabalho, operação essa para a qual não foi preparado (IANNI, 1972, p.49, 50).

O trabalho livre destinava os indivíduos a uma determinada classe social, sendo a imigração e a abolição manifestações de todo um processo, cujos objetivos eram apenas os de formar um mercado de mão-de-obra livre, e a divisão do trabalho,

[...] como uma das forças principais da história, expressa também no seio da classe dominante como divisão do trabalho espiritual e material, de tal modo que, no interior desta classe, uma parte, aparece como os pensadores desta classe, enquanto que os outros relacionam-se com estas idéias e ilusões de maneira passiva e receptiva, pois são, na realidade, os membros ativos desta classe e têm pouco tempo para produzir idéias e ilusões sobre si próprios (MARX e ENGELS, 1979, p.73).

Nesse cenário o trabalhador livre não é visto como uma pessoa humana, mas sim colocado em seu posto como apenas mais um braço, uma força de trabalho a serviço dos meios de produção da classe dominante, cuja tarefa é a de apenas suprir as necessidades existentes no sistema capitalista, que propõe a idéia de homem livre simulando uma sociedade igualitária, porém sem deixar de explorar o homem por meio de seu trabalho, só que de maneira mais sutil, discreta.

Ao propor ideologicamente a igualdade de oportunidades, a sociedade capitalista

[...] garantiria aos mais capazes, aos mais esforçados, aos que "trabalham duro", o acesso às melhores posições. A educação tornaria permeáveis as classes sociais de modo que, quem não "subisse", ou não se teria esforçado o suficiente, ou teria sido menos capaz. Porque a própria existência do "sistema de liberdade" (capitalismo), tendo acabado com os privilégios de sangue e nobreza é garantia suficiente para a eliminação de barreiras à mobilidade social. Educação formal, liberdade formal, igualdade jurídico-formal, a formalidade, a aparência encobrem a realidade concreta da sociedade de classes (ROSSI, 1986, p. 71 - grifos do autor).

Pensando nessa nova forma de trabalho, e também como justificativa para o novo caráter republicano, presume-se uma nova educação que procurará adequar à idéia de trabalho existente, e também controlar essa massa, agora de cidadãos. Educar seria então uma forma de se inculcar nas pessoas a disciplina do trabalho, visando com isso, manter a ideologia das elites dominantes. 


\section{Os Campos Gerais e a criação da cidade de Palmeira}

No município de Palmeira nos Campos Gerais-PR a presença de imigrantes europeus se deu com a formação de diversos núcleos coloniais para onde foram instalados os colonos oriundos da Rússia, Polônia, Alemanha e da Itália.

Palmeira início do século XX - Rua Coronel Vida

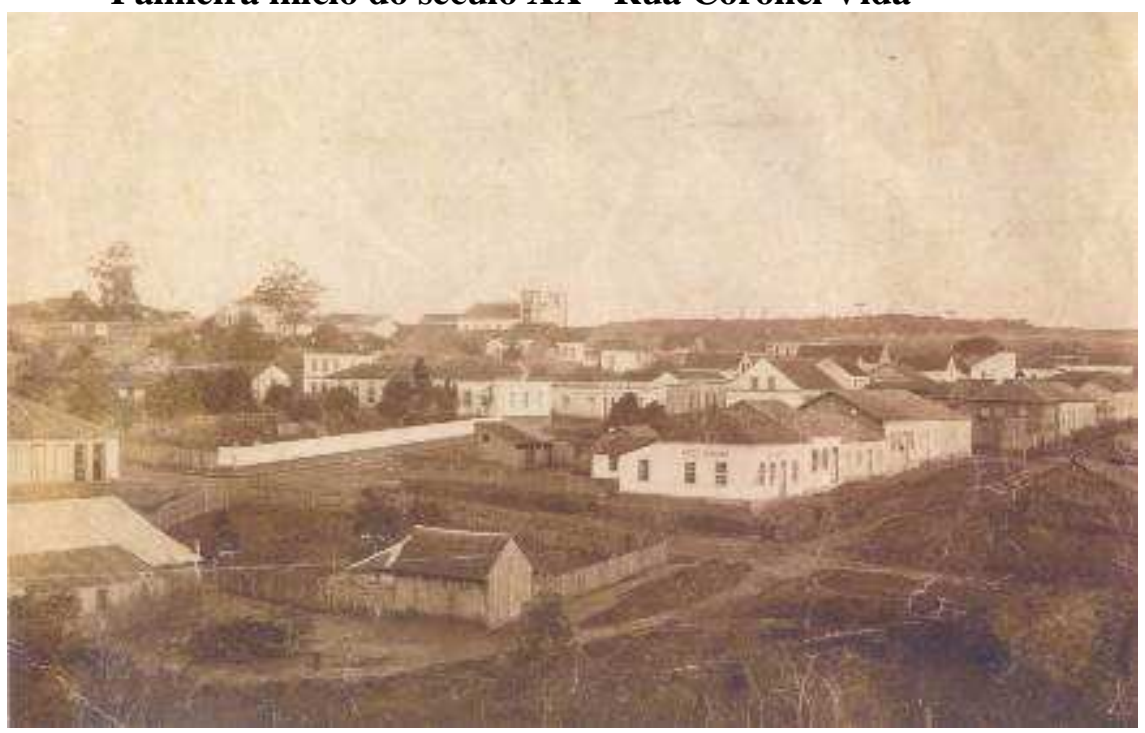

Fonte: Acervo particular cedido pelo Sr. Hugo Krambeck

A criação da primeira Colônia de imigrantes se deu em 1877, formada pelos imigrantes russo-alemães. Da divisão dessa colônia originaram-se seis núcleos coloniais, distribuídos de acordo com a religião de cada grupo de imigrantes, trabalhando no cultivo das terras, na extração e transporte da erva-mate os colonos viviam precariamente em localidades distantes da região urbana de Palmeira.

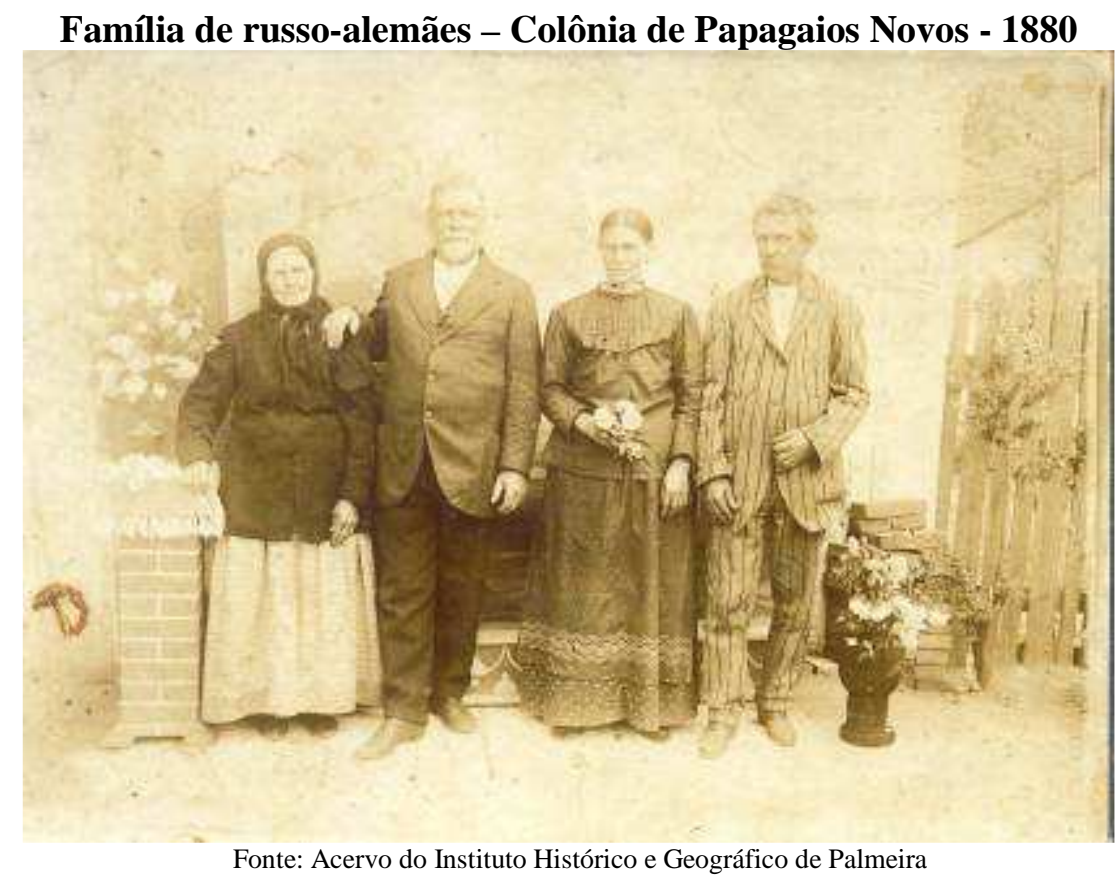


Nos primeiros anos de instalação nas colônias, a educação dos filhos dos imigrantes foi realizada nas igrejas da comunidade, cujas aulas eram ministradas pelo representante religioso, na língua nativa de cada etnia. Com o advento da república surge a questão do nacionalismo e a obrigatoriedade do ensino da língua portuguesa nas escolas de imigrantes. Por não aderirem a essa exigência muitas dessas escolas foram fechadas e os filhos dos imigrantes se viram obrigados a frequentar as escolas públicas Isoladas do estado, criadas nas regiões rurais de Palmeira.

As aulas nas escolas públicas Isoladas eram ministradas por um (a) só professor (a), o ensino primário oferecido com quatro séries dava-se ao mesmo tempo e na mesma sala, cabendo ao professor dominar os conteúdos relacionados com as quatro séries trabalhandoos simultaneamente com os alunos. Para trabalhar nas escolas isoladas os professores passavam por um concurso público, instituído em 1892, que determinava por meio do presidente do Estado a quantidade de vagas existentes nas escolas.

Para participar do concurso era necessário que o candidato apresentasse um atestado que comprovasse sua boa moral, ter dezoito anos completos, e no caso de não normalista, apresentar um documento que comprovasse suas atividades no magistério por no mínimo cinco anos.

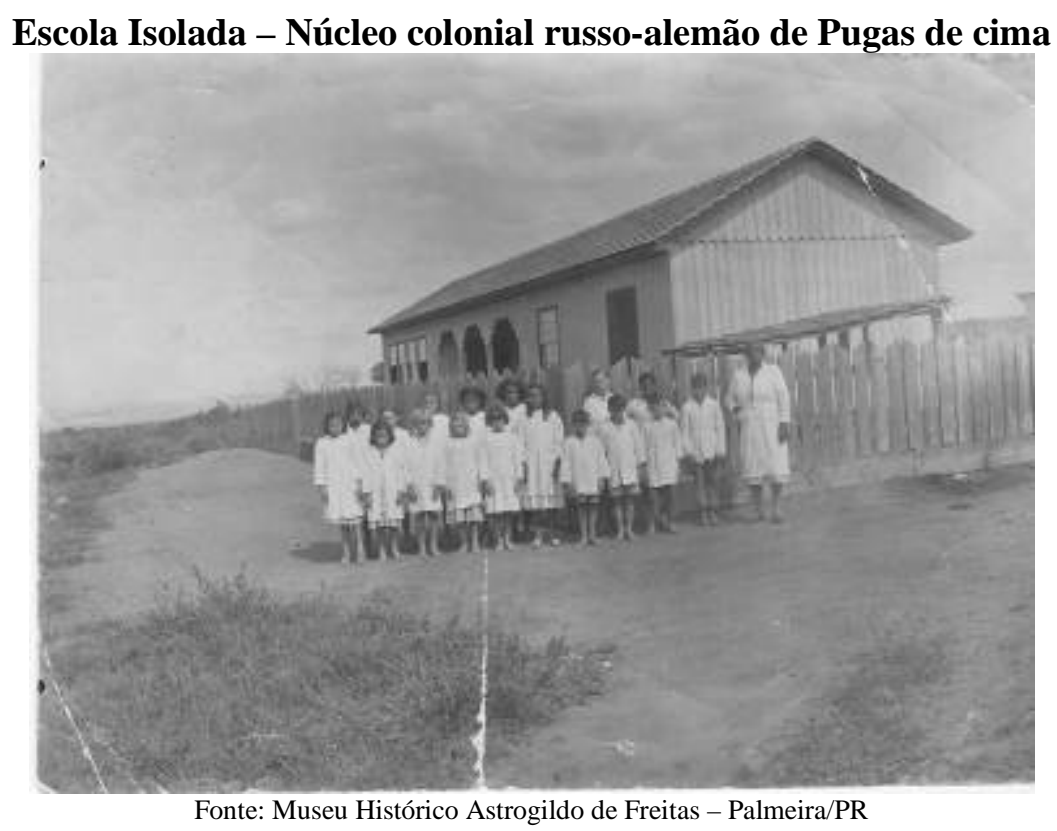

A inspeção escolar para os exames finais de aprendizagem dos alunos nas Escolas Públicas Isoladas era realizada uma vez por ano. Tratava-se de uma tarefa árdua para os inspetores escolares, visto que

As rodovias de penetração desgalham-se por campos e mattos, quase desertas até encontrarem longínquo e diminuto povoado, onde uma escola apparece como sentinella perdida, em tosca casinha de madeira, imperceptível $\mathrm{rm}$ immenso horizonte, às vezes pertada entre pinheiros na matta espessa. Os meios de condução são escassos, morosos e fatigantes. $\mathrm{O}$ viajor leva ás vezes o dia todo a caminhar sem encontrar quem lhe ofereça alimento e repouso. Perde-se facilmente no emmaranhado dos trilhos, com o coração apertado pela incerteza e receio de ser alcançado pela noute. As vezes são necessários dois dias de caminho a fio para encontrar escola modesta, izolada em zonas de diffícil accesso. Outras 
necessita que o rio baixe para transpor sem perigo. (Relatório do Inspector Geral do Ensino, Estado do Paraná, 1924, p. 32).

O espaço físico ocupado por essas escolas eram precários, neles predominava a carência total de materiais escolares, livros, cadernos, e salários para os professores. O descaso para com as mesmas, por parte do governo era evidente, no entanto as escolas Isoladas continuaram a ser criadas na cidade de Palmeira até meados do século XX, funcionando paralelamente ao grupo escolar Conselheiro Jesuíno Marcondes, criado na cidade no início do século, mais precisamente em 1907.

No início do século XX, a economia da cidade que tinha como base estrutural a agropecuária realizada nas fazendas passa a ser urbana. A população crescente precisava suprir suas necessidades básicas, nesse sentido o comércio no centro urbano passa a ser a prioridade econômica da região. Com o desenvolvimento da cidade formou uma classe burguesa, representada por comerciantes, políticos, donos de fazendas, etc., com grande poder aquisitivo, que interessados no "progresso e na modernidade" da cidade de Palmeira reivindicaram a construção de um prédio que abrigaria o grupo escolar republicano da região.

Para atender os anseios dessa classe, bem como o projeto republicano de instauração dos grupos escolares no país, o presidente do Estado do Paraná, Vicente Machado da Silva Lima, assinou o decreto $\mathrm{n}^{\circ}$ 407, de 03 de dezembro de 1904, que destinava uma verba orçamentária para a construção do primeiro grupo escolar da cidade de Palmeira.

\begin{abstract}
Decreto ${ }^{\circ}$ 407, de 3 de dezembro de 1904.
O presidente do Estado do Paraná, desejando attender as necessidades da instrução publica primaria da cidade de Palmeira e usando das atribuições que lhe são conferidas por Lei, decreta: Art. $1^{\circ}$. Fica reservada, da verba do $\S 3^{\circ}$., do Art. $5^{\circ}$., da Lei do orçamento, $\mathrm{n}^{\circ} 566$, de 8 de abril d'este anno, athe a quantia de 12:000 $\$ 000$ (doze contos de réis), para a construção de um edifício na cidade de Palmeira em terreno da Municipalidade, para nelle funcionar um Grupo Escolar. Art. $2^{\circ}$. Esse Grupo Escolar, onde funcionarão as escolas da mesma cidade, terá a denominação perpétua de "Conselheiro Jesuíno Marcondes" em homenagem ao ilustre paranaense desse nome e que tantos serviços prestou ao Paraná e que teve o seu berço naquela cidade. Art. $3^{\circ}$. A secretaria de Obras Publicas ordenara a confecção da planta, organização do orçamento e entregara a fiscalização das obras, que devem ser logo iniciadas, á Camara Municipal da cidade de Palmeira. Art. $4^{\circ}$. Revogamse as disposições em contrário. Palacio da Presidencia do Estado do Paraná, em 3 de dezembro de 1904. VICENTE MACHADO DA SILVA LIMA Bento José Lamenha Lins (Decreto de Lei nº. 407, apud, Freitas, 1977, p. 56).
\end{abstract}

Seguindo os moldes de organização das escolas-modelo do Estado de São Paulo e do Rio de Janeiro, o Grupo Escolar "Conselheiro Jesuíno Marcondes" foi construído no lote de terreno localizado na Rua Conceição, região central da cidade de Palmeira, doado pela prefeitura para a edificação do grupo escolar. Note-se que no início do século XX os municípios que mantivessem um número de pelo menos quatro escolas primárias isoladas funcionando na região poderiam requisitar a criação de um grupo escolar, desde que disponibilizassem uma área territorial para a construção do novo edifício. 


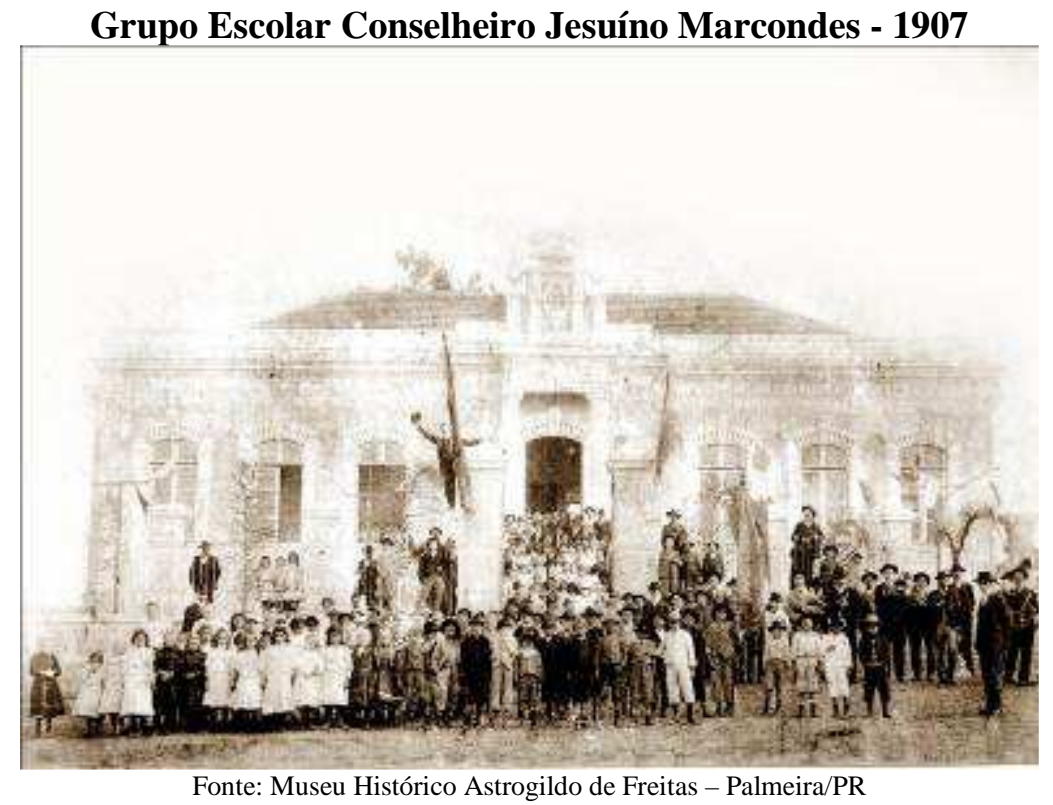

O lote de terreno destinado à construção do grupo escolar Conselheiro Jesuíno Marcondes pertenceu a uma família tradicional da cidade de Palmeira, neste local localizava-se a casa do tenente "[...] Antonio Joaquim de Camargo, genro do fundador da Palmeira, o Tenente Manoel José de Araújo, e pertencente ao tronco da família Camargo do Paraná" (Centenário da escola Jesuíno Marcondes, 2007, p. 39). O terreno amplo permitiu que a família construísse ali, no século XIX, um grande solar, uma moradia utilizada para sua permanência na cidade quando os mesmos deslocavam-se da fazenda Conceição onde residiam.

Por tratar-se de um terreno bem localizado, entre a Rua da Conceição, principal centro de comércio de Palmeira, com vista frontal da Praça Floriano e fundos da igreja Matriz da cidade, os políticos da época decidiram ser o local mais apropriado para a construção do novo grupo escolar que representaria a "modernidade" da cidade.

Para atender o projeto de modernidade que o ideal republicano propunha o grupo escolar Conselheiro Jesuíno Marcondes foi construído com toda imponência, como sinônimo de "progresso" representava a justificativa ideológica nos discursos republicanos pela valorização da educação por meio da escola pública e estatal, considerada a instituição que formaria a sociedade de Palmeira no modelo de instrução republicana. 


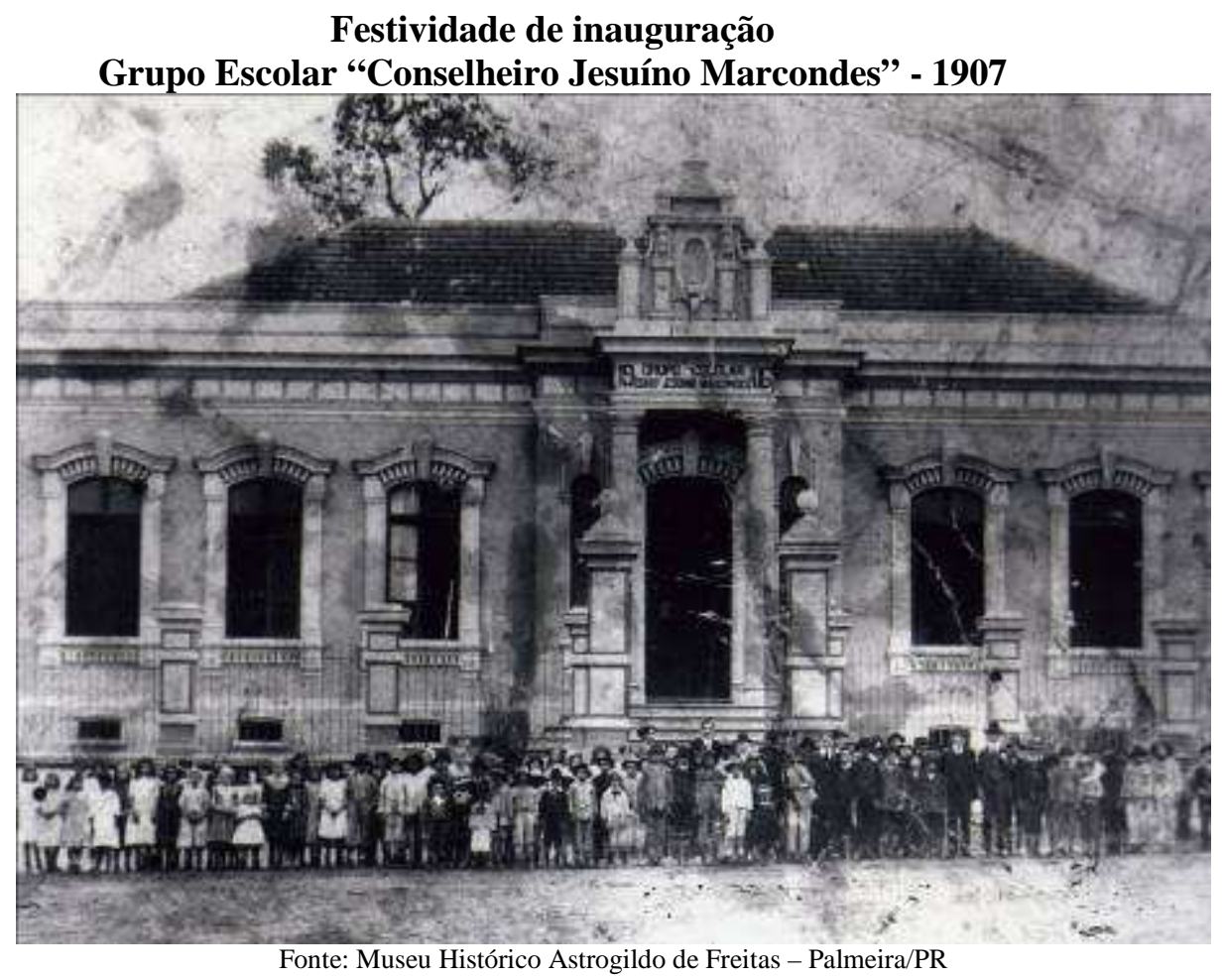

A inauguração ${ }^{\mathrm{vi}}$ do grupo escolar Conselheiro Jesuíno Marcondes foi promovida pela prefeitura Municipal de Palmeira e aconteceu no primeiro trimestre de 1907, apesar de a obra já estar concluída em 1906. A solenidade de inauguração foi feita com toda magnificência, autoridades locais e quase toda a população residente na cidade participaram da cerimônia.

Os primeiros professores que lecionaram no grupo escolar Conselheiro Jesuíno Marcondes foram: João Raymundo Ramos, professor das classes dos meninos, e Maria Luiza Rodrigues $^{\mathrm{vii}}$, que ministravam as aulas para a classe feminina. Nos primeiros anos do regime republicano ocorre uma distribuição diferenciada das classes de alunos, uma vez que as aulas a serem ministradas nas escolas do sexo feminino e das escolas mistas cabiam às professoras, enquanto a regência das escolas masculinas era permitida apenas aos professores do sexo masculino.

A primeira turma a se formar no grupo escolar, em 1912 após quatro anos de estudos, era composta por cento e dez (110) alunos do sexo masculino. A maioria dos alunos era proveniente da sociedade urbana de Palmeira, filhos dos comerciantes, de representantes políticos, donos de hotéis, padarias, açougues, etc. Pode-se dizer que os grupos escolares republicanos atenderam nas primeiras décadas de sua implantação a alunos "[...] provenientes das camadas populares, no entanto, daqueles setores mais bem integrados no trabalho urbano. Desse contingente estavam excluídos os pobres, os miseráveis e os negros. (SOUZA, 1998, p.27).

\section{CONSIDERAÇÕES FINAIS}

Em uma sociedade dividida em classes antagônicas, estudar a primeira Instituição escolar em Palmeira é pensar a educação numa época em que na sociedade brasileira predominaram as idéias burguesas.

A instituição escolar é criada então para corresponder a determinados interesses desta classe dominante. Ao defender a criação da escola pública gratuita e estatal, os 
republicanos enfatizavam em seus discursos a importância da educação como meio de "superação" das desigualdades existentes no país, no entanto caracterizada como uma escola urbana o grupo escolar Conselheiro Jesuíno Marcondes atendeu apenas as crianças que moravam nas proximidades do prédio, ficando de fora as crianças pobres que viviam nas regiões rurais, destinadas a estudar nas precárias escolas públicas Isoladas, onde predominava a carência total de materiais escolares, livros, cadernos, e salários para os professores. $\mathrm{O}$ descaso para com as mesmas, por parte do governo era evidente, no entanto elas funcionaram paralelamente ao grupo escolar republicano de Palmeira.

Nesse sentido percebeu-se durante a análise realizada sobre o grupo escolar em questão, que o mesmo não atendeu a toda a população de Palmeira, como propunha ideologicamente o ideário republicano de instauração dos grupos escolares. A democratização de oportunidades iguais de acesso às escolas públicas no Brasil não foi uma realidade concreta visto que ao se implantar a escola pública numa sociedade de classes, as desigualdades presentes anularam a "igualdade" proposta pelo ideário.

A partir dos elementos expostos nesta pesquisa, conclui-se que a criação da escola, desde a sua gênese, é correlata a divisão social do trabalho, da instituição da propriedade privada e consequentemente da divisão da sociedade em classes. Criada para atender a uma determinada parcela da sociedade percebeu-se que a escola, no transcorrer do processo histórico da humanidade, não fez mais que propagar as idéias da classe que detinha o poder nas mãos. Ao propor uma escola pública, gratuita e estatal o Estado, como representante dessa classe, propôs ideologicamente uma educação democrática que atenderia a toda a população, sem distinção de classes, no entanto compreendeu-se que esse ideário foi um aparato utilizado pelos republicanos para propagar o novo regime político, visto que seria impossível, como já colocado, atender aos interesses de toda uma sociedade que estruturalmente está dividida em classes, ou seja, burguesia e proletariado, ricos e pobres.

\section{REFERÊNCIAS}

BAPTISTA, Vera Biscaia Vianna. Curitibanos dos Campos Gerais. Curitiba: Fundação Cultural, 2002. 192p.

Centenário da escola Jesuíno Marcondes. Instituto Histórico e Geográfico de Palmeira. Prefeitura Municipal de Palmeira, 2007.

ENGELS, Friedrich. A origem da Família, da Propriedade Privada e do Estado / Friedrich Engels; tradução de Leandro Konder - 12. ed. - Rio de Janeiro - RJ: Bertrand Brasil S.A, 1991.

FREITAS, Astrogildo de. Palmeira Reminiscência e Tradições. Curitiba: Instituto Histórico Geográfico e Etnográfico Paranaense. EP 4 - Estante Paranista, Lítero - Técnica, 1977.

IANNI, Octávio. Raças e classes sociais no Brasil. 2. ed. Rio de Janeiro, Ed. Civilização Brasileira S.A, 1972.

LOMBARDI, Jóse Claudinei. Marxismo e história da educação: algumas reflexões sobre a historiografia educacional brasileira recente. Campinas: Tese de doutorado, Universidade Estadual de Campinas, UNICAMP, 1993.

MANACORDA, Mario. Alighiero. História da Educação: da antiguidade aos nossos dias / Mario Alighiero Manacorda; tradução de Gaetano Lo Monaco; revisão da tradução Rosa dos Anjos Oliveira e Paolo Nosella - 5. Ed. São Paulo: Cortez, 1996. 
MARX, Karl. O Capital, Livro 1 vol, I e II, Rio de Janeiro: Civilização Brasileira,1968.

MARX, Karl e ENGELS Friedrich. Manifesto do partido comunista. Cap. I. Burguesia e proletariado, Calvino, 1975.

A ideologia alemã. 2. ed., Livraria Editora Ciências Humanas Ltda. São Paulo - SP, 1979.

NASCIMENTO, Maria. Isabel. Moura.In: Diana Gonçalves Vidal, (org.). Grupos Escolares: cultura escolar primária e escolarização da infância no Brasil (1893 - 1971). Campinas, SP: Mercado de Letras, 2006.

PONCE, Aníbal. Educação e Luta de Classes. / Aníbal Ponce; Traduzido do original em espanhol/ publicado por J. Hector Matera - Buenos Aires, 1957. Tradução para a língua portuguesa de José Severo de Camargo Pereira - São Paulo: Fulgor, 1963.

Relatório do Inspector Geral do Ensino. Estado do Paraná. Cesar Prieto Martinez. Typ. Da Penitenciaria do Estado, 1924. - Arquivo Público o Paraná

ROSSI, Wagner Gonçalves. Capitalismo e Educação: contribuição ao estudo crítico da economia da educação capitalista. 2 ed. São Paulo: Moraes, 1986.

SANTANA, Luiz Carlos. Liberalismo, ensino e privatização: um estudo a partir dos clássicos da economia política. Tese (doutorado). Universidade Estadual de Campinas - UNICAMP. Campinas, 1996.

SAVIANI, Dermeval. História das idéias pedagógicas no Brasil / Dermeval Saviani. - 2. Ed. Ver. E ampl. - Campinas, SP: Autores Associados, 2008. - (Coleção memória da educação).

In. NASCIMENTO, Isabel Moura. [et al.], (orgs). Instituições Escolares no Brasill: conceito e reconstrução histórica. Campinas, SP: Autores Associados: HISTEDBR; Sorocaba, SP: Uniso; Ponta Grossa, PR: UEPG, 2007. - (Coleção memória da educação).

SCHELBAUER, Analete Regina. Idéias que não se realizam: o debate sobre a educação do povo no Brasil de 1870 a 1914/ Analete Regina Schelbauer. Maringá: EDUEM, 1998.

SOUZA, Rosa de Fátima. Templos da civilização a implantação da escola primária (18901910). São Paulo: UNESP, 1998.

VIDAL, Diana Gonçalves. Grupos Escolares: cultura escolar primária e escolarização da infância no Brasil (1893 - 1971) / Diana Gonçalves Vidal, (org.). - Campinas, SP: Mercado de Letras, 2006.

ARQUIVOS CONSULTADOS

Instituto Histórico e Geográfico de Palmeira

PR 151, Km 82 - Prédio da Antiga Estação Ferroviária de Palmeira

Palmeira - Paraná.

Museu Histórico de Palmeira - Dr. Astrogildo de Freitas

Praça Raul Braz de Oliveira, s/n. Centro.

Palmeira - Paraná

Revista HISTEDBR On-line, Campinas, número especial, p. 128-141, mai2012 - ISSN: 1676-2584 140 


\section{Notas}

${ }^{\text {i }}$ O projeto "Reconstrução Histórica das Instituições Escolares Públicas dos Campos Gerais - PR (19041950)", desenvolvido no período de set/2006 a jan/2010, teve por objetivo a realização da reconstrução histórica das Instituições Escolares na Região dos Campos Gerais, do Estado do Paraná, no período compreendido entre o início da República até a década de cinqüenta do século XX. O trabalho de campo consistiu no levantamento, catalogação e digitalização de fontes históricas das dezenove Instituições escolares da Região dos Campos Gerais do Paraná; na análise das fontes coletadas para a reconstrução histórica das Instituições; na conscientização da comunidade escolar da importância da conservação do acervo documental da escola.

ii A região dos Campos Gerais no Paraná estende-se para o norte até encontrar as florestas da Bacia do Itararé e Paranapanema, e, para o sul, as Florestas do Rio Iguaçu. A oeste, encosta nos Campos de Guarapuava e na Serra da Boa Esperança, e sua porção oriental faz divisa com a Serra de São Luís do Purunã, com predomínio do Rio Tibagi (BAPTISTA, 2002, p.15).

iii Com a escassa produção de alimentos as tribos vencidas num confronto eram saqueadas e seus moradores mortos, a partir da produção excedente de alimentos e a falta de mão-de-obra, essa concepção mudou.

iv "Intelectuais" no sentido de serem mais instruídos do que a maioria das pessoas.

${ }^{\vee} \mathrm{O}$ Estado nasce diretamente e fundamentalmente dos antagonismos de classes que se desenvolviam no seio mesmo da sociedade gentílica. Não é um poder imposto à sociedade "[...] de fora para dentro; é antes um produto da sociedade, quando esta chega a um determinado grau de desenvolvimento. É a confissão de que essa sociedade se enredou numa irremediável contradição com ela própria e está dividida por antagonismos irreconciliáveis que não consegue conjurar" (ENGELS, 1991 p.191).

${ }^{\text {vi }}$ Por trinta e sete anos as atividades educativas foram ministradas no prédio construído em 1906. No dia 27 de agosto de 1938 ocorreu a inauguração do novo prédio construído na Rua Jesuíno Marcondes, cujo espaço físico contou com oito salas de aula; salão de festas, banheiros; cozinha e refeitório; e salas administrativas.

vii Cabe ressaltar que os professores citados, não eram normalistas, lecionavam nas duas escolas isoladas de Palmeira, cujo agrupamento realizou-se com a criação do grupo escolar.

Recebido em: $\quad 23.04 .12$

Aprovado em: $\quad 30.05 .12$ 